\title{
Images et icônes
}

From images to icons

\section{Michel Cadé}

\section{CpenEdition}

\section{Journals}

Édition électronique

URL : https://journals.openedition.org/rhcf/89

DOI : 10.4000/rhcf.89

Éditeur

Rails \& histoire

Édition imprimée

Date de publication : 1 décembre 2007

Pagination : 64-66

ISSN : 0996-9403

Référence électronique

Michel Cadé, «Images et icônes », Revue d'histoire des chemins de fer [En ligne], 36-37 | 2007, mis en ligne le 10 mai 2011, consulté le 22 avril 2022. URL : http://journals.openedition.org/rhcf/89 ; DOI : https://doi.org/10.4000/rhcf.89 


\title{
Images et icônes
}

\author{
Michel Cadé \\ Professeur d'histoire contemporaine à l'université de Perpignan \\ Via Domitia
}

Les rails, le train, les cheminots, le paysage qui défile, étrange impression d'un mouvement immobile, l'entrée du train en gare, image archétypale de la rencontre de l'art et l'industrie, autant d'images qui structurent, plus que d'autres, le regard du premier vingtième siècle sur lui-même. Deux films de fiction vont construire dans le premier aprèsguerre l'image du couple mythique que constitue le conducteur et sa locomotive : La Roue d'Abel Gance (1922) et La Bête humaine (1938) de Jean Renoir. Dans le flamboiement des images du premier comme dans le naturalisme apparent du second c'est d'abord la folie du monde industriel qui est mise en scène, à travers celle de personnages mus par une sorte de fatum en dernière instance mécanique. Le monde du chemin de fer, quel que soit le soin vériste avec lequel il est filmé, est ici plus décor qu'acteur véritable, prétexte plus que sujet et, si le cheminot se retrouve en Gabin jusqu'à l'identification, l'absence d'une vue cavalière du réseau comme des hommes qui le constituent empêche d'en avoir une image globalisante. Il appartenait au temps du bouleversement social, des espoirs infinis en l'homme au travail, au temps du Front populaire, et au temps de l'ombre, où sous la cendre couve l'étincelle de la liberté, aux années noires de Vichy et lumineuses de la Résistance, temps d'exception, d'offrir des hommes du rail, de leur action, de leur environnement, des images autres, plus collectives, plus soudées, plus humbles et plus glorieusement héroïques dans leur quotidienneté que celles des héros de celluloïd de la fiction. Ce furent, en 1937, Sur les routes d'acier de Blaise Peskine, produit par la CGT, et, en 1942, Ceux du rail, film de fin d'études en forme de documentaire de René Clément et d'Henri Alekan.

Sur les routes d'acier s'inscrit dans une double mouvement : celui, interne au syndicalisme cheminot, de la création de la SNCF, considérée comme une victoire de la corporation ; celui, largement partagé par les organisations syndicales et partis de gauche, de l'utilisation du cinéma comme moyen d'éducation, de propagande voire de revendication dont témoignent, entre autres, La Vie est à nous de Jean Renoir (1936), Les Bâtisseurs de Jean Epstein (1938) ou Les Métallos de Jacques Lemare (1938). 
Au premier tient le caractère didactique du film, que l'on trouvait déjà dans $L a$ Vie est à nous, traduction en images de la fonction éducative du parti et/ou du syndicat, sans doute accentué par le fait que Blaise Peskine était ingénieur et croyait au pouvoir explicatif des schémas et tableaux. Ceux-ci rythment le film et, à diverses reprises, l'emportent sur les images « classiques », lorsqu'il s'agit d'esquisser une histoire des chemins de fer, quand est présentée la nouvelle économie du réseau conséquence de la nationalisation, enfin dans la partie qui met en chiffres la croissance et l'implantation du syndicat. Le contraste est singulier entre des plans tournés en extérieur et cet étalage abstrait de signes évoquant la suffisance de l'inévitable power point contemporain et participant de la croyance naïve en l'efficacité des flèches et des encadrés. Nul doute que le souvenir des plans, souvent magistraux, de paysages et d'ouvrages d'art, destinés à faire mesurer l'ampleur et la puissance du nouveau réseau unifié, n'ait été dans la mémoire des spectateurs d'une toute autre portée. Traçant une image à la fois de diversité, les paysages, et d'unité, la succession des ouvrages d'art, présentés en des raccourcis audacieux passant de la vallée du Rhône ou du Massif central à la Cerdagne sans transition, mais filmés toujours avec un sens sûr de la beauté des lieux et des monuments, l'équipe réalisatrice du film offrait à la nouvelle société nationale un hymne aux accents triomphants où l'importance des réalisations passées était garante d'un avenir radieux.

C'est plus dans la tradition syndicale que s'enracinent les images du travail, des travaux devrait-on dire, qui constituent l'autre versant de Sur les routes d'acier. La volonté de n'oublier personne, ni les agents des voies, ni ceux des gares, ni les aiguilleurs ou les lampistes, conduit à insérer dans un vaste ensemble le conducteur et le chauffeur, ces héros du cinéma de fiction. Ici, c'est le groupe des travailleurs des chemins de fer, au risque permanent de l'accident de travail, qui est le héros et non un individu. Dans le sens de la responsabilité collective, les cheminots sont dépositaires de la vie des passagers, dans la cohésion du groupe peut se lire, par delà celle du métier, l'image de la classe ouvrière et de sa capacité à prendre en charge le destin de la société toute entière. Révélateurs sont dans cette optique les plans qui montrent côte à côte syndicaliste cadre et syndicaliste ouvrier, affirmation radicale à l'écran de l'alliance de classe qui fonde le Front populaire. Image d'un moment, dira-t-on, mais, dans une expression moins naïve qu'il n'y parait, image destinée à durer, matrice d'un certain regard sur le monde du rail dont on pourrait trouver peut-être déjà chez Renoir le reflet. Images aussi qui nourrissent regard et passion, comme le montre le débat qui 
spontanément s'engagea lors de notre séminaire à la (re)vision du film, non seulement sur ses conditions de réalisation, sur les enjeux politiques et syndicaux qu'elle sous-entendait, sur la résonance qu'il pouvait avoir dans un présent marqué à son tour par le rôle primordial des cheminots dans le conflit social, mais aussi sur la ligne de haute montagne catalane, dite du Train jaune, et ses chances d'être inscrite par l'Unesco dans le patrimoine de l'humanité. Les images d'hier ne cessent d'être promesse d'avenir.

Avec Ceux du rail on demeure dans le même univers si les temps ont changé. Véritable documentaire sur la vie des roulants à bord des trains de la ligne Nice-Marseille, ce film est aussi un acte de résistance. En effet ses auteurs profitaient d'une autorisation de prise de vue pour filmer les casemates italiennes et allemandes le long de la ligne et ainsi renseigner Londres. Montrant les différents acteurs de la vie de la ligne, à la gare, au dépôt, sur les voies et dans les trains, jouant avec habileté de l'échelle des plans, s'appuyant sur la rhétorique du champ / contrechamp, maitrisant les éclairages en bons professionnels, René Clément et Henri Alekan se plaçaient dans la lignée des plans les plus significatifs de Sur les routes d'acier, mais la manière plus ramassée de leur propos lui donnait une efficacité plus grande. Construit autour de la figure du conducteur et de son chauffeur, fortement individualisés comme leur locomotive, l'œuvre de René Clément et Henri Alekan renouait avec l'héroïsation caractéristique du cinéma de fiction mais aussi induite par l'époque et les hauts faits d'une résistance qui, pour être l'armée des ombres, n'en était pas moins alors porteuse d'une manière héroïque. Bout d'essai avant le coup de maitre que constituera Bataille du rail (1945), Ceux $d u$ rail est aujourd'hui une œuvre à lectures multiples qui mérite d'être aussi vue pour elle-même, image de la continuité en temps de guerre d'une organisation civile, image aussi de la détermination à ne pas accepter son sort d'une classe ouvrière qui se vit comme dépositaire de l'avenir.

Dans ces deux films, enracinés dans le double discours du Front populaire et de la Résistance, le refus de la neutralité appuyé sur la force de vérité que revêt la forme documentaire institue le cheminot en icône de la classe ouvrière et le réseau ferroviaire en représentation de la nation, anticipant et préparant le discours de Bataille du rail qui allait imposer cette représentation pour au moins deux décennies. 